\title{
21
}

\section{Minority Contact Languages, Small Islands, and Linguistic Ecology}

\author{
Joshua Nash
}

\section{On Defining Minority Languages and Minority Language Linguistics}

Minorities and their cultures have received much attention in the social sciences in recent times. Still, what constitutes a minority language and a minority culture is far from clear. A reasonable working definition conflates minority languages with endangered languages. Such languages normally have small speaker numbers, are often not transmitted across generations, are frequently ridiculed both by outsiders and the language speakers themselves, and are commonly considered Indigenous ${ }^{1}$ to the place and culture where they are spoken.

These assumptions are used to explore the three major concepts of this chapter: minority contact languages; the role of the natural environment, small societies, and isolation in language development and change; and linguistic ecology or ecolinguistics (see also Bradley, this volume). The minority contact languages of the South Pacific considered here are the historically and

\footnotetext{
This chapter draws significantly on a paper 'Is Norf' $k$ an Indigenous Language?', presented by the author at the Society for History and Linguistics in the Pacific conference, University of Adelaide, 5 July 2012.
}

J. Nash $(\bowtie)$

Aarhus Institute of Advanced Studies (AIAS), Aarhus University, Aarhus C, Denmark e-mail: joshuanash@aias.au.dk 
linguistically related Pitcairn and Norfolk, the languages of Pitcairn Island and Norfolk Island, respectively. Norfolk, also spelled Norf'k, stems from the language that emerged on Pitcairn Island from 1790 in a small community comprised of Polynesian and English speakers after the famous mutiny on the Bounty in 1789. All the Pitcairn Islanders were moved to Norfolk Island in 1856. This marks the beginning of Norfolk as a form of Pitcairn, also spelled Pitkern, which has undergone changes due to its transplantation to a new environment.

These languages are the linguistic artefacts of their parallel minority cultures. Their existence problematises what a minority language may be more generally and how their island origins affect their minority status. This foundation is used to explore how such languages can be perceived in terms of their ecological embeddedness within requisite natural and sociocultural environments. Several key (eco)linguistic assumptions borne out of the author's long-term research engagement with ecolinguist-creolist Peter Mühlhäusler are summarised, a relationship founded in 1999 and based in mutual collaboration on the Pitcairn and Norfolk languages and cultures. This chapter is submitted as a general summary of almost two decades of research and thinking involving ecolinguistic relations and how such views relate to research on minority (island) contact languages and specifically contact Englishes of the Pacific.

Research into Pitcairn and Norfolk suggests they cannot be considered simple cases of language contact, language development, or creolisation. Since these ways of speaking do not have obvious social and linguistic role models because they have not originated and developed in more typical language contact environments with authoritarian control like missions or plantations, it is not clear whether they are the same, different, or are a combination of any number of dialects, sociolects, or family lects. Whatever these languages are, the expression language is used as a term of convenience. What is apparent is that traditional classificatory tools like pidgin, creole, mixed language, or a variety of English fail to represent adequately what these ways of speaking are historically, how they function, how they are used in daily life, and how they might be classified scientifically. As such, and specifically related to minority languages, Pitcairn and Norfolk question to what degree describing ways of speaking is useful in understanding languages. Recently developed minority languages spoken by minority peoples, particularly those in remote island environments and with small populations, consolidate this linguistic quandary.

As regards the reclamation, maintenance, and revival of Australian Aboriginal languages, the majority of Aboriginal languages on the Australian mainland are either dead or severely threatened (see e.g. Wigglesworth's chap- 
ter in this volume). Of the 250 languages once spoken, only around 15 are still passed on in their traditional form intergenerationally. It is not at all certain whether any of these languages will survive for more than two generations. The situation for Norfolk, by contrast, is far less bleak. Linguists, language planners, and anthropologists use a number of vitality-measuring instruments. The United Nations Educational, Scientific and Cultural Organization (UNESCO) officially recognised Norfolk's degree of endangerment more than a decade ago (in 2007), employing the following criteria:

Factor 1. Intergenerational Language Transmission

Factor 2. Absolute Number of Speakers

Factor 3. Proportion of Speakers within the Total Population

Factor 4. Trends in Existing Language Domains

Factor 5. Response to New Domains and Media

Factor 6. Materials for Language Education and Literacy

A different set of criteria used by Ethnologue, the Expanded Graded Intergenerational Disruption Scale (EGIDS), lists Norfolk as "Category 6a (vigorous), meaning that the language is used for face-to-face communication by all generations and the situation is sustainable". Although Pitcairn is not officially recognised as endangered, its future is much less promising than Norfolk's. There are fewer than 30 speakers of the language and almost no people of child-bearing age. With mainly passive language knowledge in the five-odd Pitcairn Island children on the island, according to the EGIDS, the vitality of Pitcairn lies between "Category 7 (shifting) - the child-bearing generation can use the language among themselves, but it is not being transmitted to children" and "Category 8a (moribund) - the only remaining active users of the language are members of the grandparent generation and older".

Although the reasons Pitcairn and Norfolk have become endangered are multifaceted, their social stigma and denigration have affected their vitality tremendously. Still, Pitcairn and Norfolk speakers are proud of their idiosyncratic ways of communicating. Latham (2005: 97) notes that:

Membership of the Society of Pitcairn Descendants is reserved for those with Pitcairn ancestry - anyone who can trace their blood back to the settlers of 1856. The society aims 'to promote knowledge of the Pitcairn race' and claims Pitcairners are indigenous to Norfolk Island. 'It's not a claim,' says Ric [Robertson] in response to the use of the 'c' [claim] word. 'It's a fact. We were the first people as a whole to settle on Norfolk Island as a permanent homeland - now if you want a definition of indigenous that's it, isn't it?' 
Mühlhäusler's documentation work and community involvement on Norfolk Island associated with increasing the awareness of the importance of Norfolk in education and in the island's society at large has been successful. This author's recent documentation work of Pitcairn on Pitcairn Island and in the New Zealand and Australian diaspora is likely to bear fruit in terms of language revitalisation. Yet, with such a small population and almost no children speakers, Pitcairn's future is doubtful.

\section{Are Pitcairn and Norfolk Languages?}

In order to make sense of and possibly answer the question 'Are Pitcairn and Norfolk languages?', it is necessary to define what can be implied by using the word language. A working definition is that a language as primarily the spoken but also the non-verbal and written method of expression and communication used by a particular group of people. What is not clear, however, is what and how the reification of the concept of a language can represent and account for ways of speaking, and how such accounts can help us understand the study of language types. Scholarly interest into Pitcairn and Norfolk has led to different ways of dealing scientifically with the concept of languages including philosophical, ontological, and typological treatments (e.g. Harrison 1985; Laycock 1989; Mühlhäusler 2007a, 2011; Nash 2016).

When a small group of British sailors and their Polynesian consorts exiled themselves on Pitcairn Island, a new society and a new language emerged within a generation. After the move to Norfolk Island, several families backmigrated to Pitcairn Island in the 1859 and 1864. For almost 150 years, there was little contact between the descendants of these two groups. Both groups experienced some contact with speakers of other languages and the language varieties spoken by missionaries, people on passing ships, and visitors. The Norfolk variety continues to be spoken on Norfolk Island today by approximately 400 descendants of the Pitcairners. Using the word 'approximately' is appropriate here because it is not at all clear what a speaker of Norfolk is, or, indeed, when a person is speaking Norfolk or the variety of English used on the island. Around 30 people speak Pitcairn on Pitcairn Island.

The language situations on both islands are diglossic in the sense that the same speakers use Pitcairn and Pitcairn Island English and Norfolk and Norfolk Island English under different conditions. For example, the Pitcairn Island English statement "we're going down Landing" (the longboat launch at Bounty Bay) is influenced by Pitcairn in at least two ways: the obligatory use 
in Pitcairn of the spatial descriptor 'down' to specify the location relative to the speaker is chosen and transferred to Pitcairn Island English, which is not obligatory if the standard English 'to' were used; the absence of the definite article-'Landing' instead of 'The Landing' - is grammatically aberrant in other varieties of English but acceptable in Pitcairn Island English, because of the effect of Pitcairn. Similarly, the use of obligatory Norfolk spatial prepositions such as "he out Mission" (he's [out] at the Melanesian Mission area in the southwestern part of Norfolk Island) and "she up in a stick" (she's [up] in the wooded areas in the northern part of Norfolk Island) are transferred to Norfolk Island English although they are not obligatory. The Norfolk Island English "he's out at the Melanesian Mission" and "he's at the Melanesian Mission" are polysemic. The choice of language on both islands depends on the situation and the linguistic abilities of the interlocutor. It is not clear whether Pitcairn and Norfolk are high (acrolectal) and low (basilectal) varieties of English when compared to the more standard varieties of English spoken.

The following examples emphasise the difference between English and Norfolk:

English: Where are you two going? We are going to Kingston, to Anson Bay, to the airport, to Pitcairn Island, to Aunt Em's place.

Norfolk: Bout yorlye gwen? Himii gwen Doun ar Toun, out Anson, roun ar droem, up Pitcairn, up Aunt Em's.

English: What do you call this place? Kingston, Cooks Monument?

Norfolk: What name des side? Doun ar Toun, out Cooks.

Once again, fixed spatial prepositions are used in Norfolk which contrasts with English.

Pitcairn and Norfolk are mutually intelligible. However, lexical and grammatical differences are significant; there are distinct variances in article grammar (e.g. the Pitcairn definite article $h a$ is phonologically and syntactically different from the Norfolk definite article dar), divergent phonology especially vowel quality, for example, Pitcairn's 'stone' [sto:'n] compared to Norfolk's 'stone' [stø:'n], and unalike anthroponymous and biotic lexicon and expressions because of the dissimilarities in the islands' cultural and physical environments. The Pitcairn expression "you gut Fred feet" (you've got very big feet), named after Frederick Christian born 1883, is not found in Norfolk, just like the Norfolk "you Lucy'en" (you're crying in public or weeping) from the meaning "to cry in public or to be weepy" after the one-time habit of a now deceased Norfolk Island woman, Lucy, is not used in Pitcairn. 
Because of the unfocused nature of Pitcairn and Norfolk and their few linguistic role models across their history, the languages are anomalies to more standard varieties of English and to linguistic studies of all these varieties. Asking 'Are Pitcairn and Norfolk languages?' is a probing method to understand not only how small (island) languages can operate within the social and natural environments they exist but also what assumptions linguists place on the characterisation of these particular ways of speaking and more generally any other hard-to-pin-down linguistic anomalies. Pitcairn and Norfolk are different and mutually unintelligible enough from the Englishes used on the respective islands to be reasonably considered separate languages in their own right. Additionally, Pitcairn and Norfolk as dominant cultural markers, social space delineators, and minority ways of communicating, which can speak about and be researched in terms of their political and historical connection to place, have a meaningful presence separate from other more mandated linguistic norms such as those associated with using English.

\section{Are Pitcairn and Norfolk Indigenous Languages? Politics and Place}

Because of Norfolk Island's political connection to Australia as an external territory, this island's linguistic history constitutes a de facto element in the continent's linguistic history. Similarly, owing to its linguistic and historical relationship to Norfolk Island, Pitcairn Island is related to Norfolk Island and thus Australia. The politics of these language, people, and place relationships are critical when attempting to describe the minority status of these languages.

The position of Australian (Aboriginal) Indigenous languages has been at issue for several decades. Because of the importance of claims to country, native title legislation, and documenting endangered languages, linguists, anthropologists, and cartographers are often puzzled where boundaries between groups lie, how these boundaries can be mapped, and what the purpose of creating boundaries actually is. Such questions and considerations are central when documenting Indigenous languages and any ill-understood or lesser-known language. What seems even trickier is how to conceptualise Indigenous contact languages, for example, Gurindji Kriol, varieties of Northern Territory Kriol, and Aboriginal English (see also Wigglesworth's chapter in this volume). Like many other Indigenous languages spoken 
in Aboriginal and First Nation communities elsewhere in the world, these languages not only have no official standing but often have no social standing, even in the opinion of the speakers of the languages themselves. Some speakers even believe these languages, which they speak, and which linguists are trying to document, do not exist (Dobrin et al. 2007) or that they speak 'shit language' (Mühlhäusler 2005: 7). Like Walsh (2005), who asked "will Indigenous languages survive?", it can be maintained that the effectiveness of minority language revitalisation and documentation and engagement with the language speakers, whether they are Indigenous to the location where they use their language or not, is as much political engagement as linguistic commitment.

No languages spoken by Indigenous Australians are accorded official or even co-official status under the Australian Constitution. Moreover, no language- even English—has official constitutional or legislative status. Norfolk Island has since 1913 been administered as an external territory of Australia. It is thus politically and geographically a part of Australia. Norfolk is the only language recognised by legislation within Australia. Not even English has any definite legislative status afforded to it by the Australian Constitution, except in that granted it by the Norfolk Island Language (Norfolk) Act (2004) (Administration of Norfolk Island 2004) ('The Act', presented in full in the appendix). This places Norfolk in an odd category; it is official on Norfolk Island, and so along with the Norfolk Island variety of English, which is acknowledged in The Act, it is the only language in Australia to have any legislative status. None of the 20-plus Indigenous Australian languages still spoken have any similar status. Despite this significant fact, Norfolk remains poorly documented, described, and understood. As a way of speaking, its future has remained and is still unsure and insecure; what (generally lexical) documentation has been achieved over the past two decades by linguists Mühlhäusler and this author with the assistance of the Norfolk Island community has taken a large amount of time and has not seen a respective increase in the absolute amount of Norfolk spoken. What this does question and require is a deeper understanding of the role of language scholars and linguistic science in not only comprehending their object of study as political entities but also methods by which (small island contact) languages and minority language varieties and their grammatical and social typologies can be appreciated. In 1996, Pitcairn was loosely accorded official status without the need for a referendum or any requisite legislation. It is officially spelled 'Pitkern', and has since been an official language of this British Overseas Territory (see e.g. Källgård n.d.). 
Although there are many parallels between Pitcairn and Norfolk and Australian (Indigenous) languages and other Indigenous languages in how the languages and their speakers were and are possibly still perceived and treated by non-Indigenous people, Norfolk is not related socially or typologically to any (Australian) Indigenous language. Its social and ecological history means it cannot be considered Indigenous to Australia as Australian Indigenous languages are. Because of the grammatical and lexical influence of non-European varieties in Pitcairn, Norfolk's social and typological status in relation to the linguistics and geography of Polynesian and Oceanic languages is trickier than Norfolk's connection to Australian Indigenous languages. Although Norfolk is spoken by approximately 400 people and Pitcairn by around 30 speakers, the languages are integral to Australia's and the United Kingdom's linguistic heritages, respectively.

I do not claim that Norfolk is Indigenous in the same sense that other Australian Aboriginal languages such as Guguda or Arrente still spoken today are Indigenous to Australia and that Pitcairn is Indigenous to Pitcairn Island in a similar manner to how Tahitian and other Polynesian ways of speaking are connected to Tahiti and Greater Polynesia. However, because of place and people relations, reflecting on the term Indigenous as applied to Australian Indigenous languages and other minority languages with respect to the politics and place of Pitcairn and Norfolk should be rewarding both for linguists and anthropologists researching (Australian) Indigenous languages and place and scholars of the politics of language. Because of the official recognition of Pitcairn by the Pitcairn Island Government in 1996 and of Norfolk through The Act, the position of the languages problematises not only the linguistic status of (minority and Indigenous) languages in British Overseas Territories and Australia but also the political status and role of Pitcairn and Norfolk in relation to such minority languages. ${ }^{2}$

Norfolk is a poignant case in point. It is the language "spoken by the descendants of the first free settlers of Norfolk Island who were descendants of settlers of Pitcairn Island" (The Act, paragraph 4). ${ }^{3}$ The language is legally allowed to be used in governmental and political dealings on Norfolk Island by the Norfolk Island Government. According to the Act, "The Norfolk Island Language may be used in all forms of communication between persons of Norfolk Island (but need not be) but when used in official [legal and political] communications [it] must always be accompanied by an accurate translation in the English language" (The Act, paragraph $5(1)){ }^{4}$ 


\section{Sociohistorical Issues in Minority Languages: Pitcairn and Norfolk}

Like other minority languages in Australia and the Pacific, Pitcairn and Norfolk have been looked down upon socially. Up until the 1960s, both languages and cultures were not celebrated and were severely stigmatised by outsiders and even insiders themselves. Pitcairn and Norfolk have received many names, some of which have strongly misrepresented what the language is socially and linguistically. Names like Pitcairnese and Norfolkese, Pitcairn and Norfolk patois, Pitcairn and Norfolk creole, gibberish (Marrington 1991: 12), bad English, and the expression 'breaking da King's crown' meaning 'to speak Norfolk' have existed in parallel with the ridicule associated with speaking the language (Flint 1964: 209). ${ }^{5}$ The Norfolk Island education system, which is administered by the New South Wales Government, has been at the heart of much of this derision by outsiders (Mühlhäusler 2007b, 2015). The Pitcairn Island education system, administered by the New Zealand government, has also not been until around the 1980s supportive of the use of Pitcairn in the Pitcairn Island school. Despite measures such as language and toponymic documentation (e.g. Nash 2013 for Norfolk; Nash 2017 for Pitcairn), teaching Norfolk at the Norfolk Island Central School (e.g. Mühlhäusler 2007b), and the creation of education tools such as picture books (Meralda Warren's 2007 Mi Bas Side orn Pitcairn [My Favourite Place on Pitcairn] on Pitcairn Island; Gaye Evans's 2009 Orn'sehn [At the Beach] on Norfolk Island), a Norfolk school grammar (Eira et al. n.d.), and the attempt at establishing a consistent writing system for Norfolk (Mühlhäusler n.d.) and Pitcairn (Källgård n.d.), which has not been entirely successful, the domains of use of Pitcairn and Norfolk and the absolute number of Norfolk speakers have decreased. This trend continues, which is ironic because there has been a conscious embracing of the language as a social emblem associated culturally and aesthetically with the island; the Norfolk Island community themselves and many outsiders like the language and they like to hear it spoken. The language situation on Pitcairn Island is significantly different to Norfolk Island; although speaker numbers are not high, they are relatively stable because there are so few people resident on the island. Diminishing speaker numbers is largely the result of deaths within the community.

Looking specifically at Norfolk, it is observed that this decrease characterises one of the most important and intricately implicit social functions of the language: because it is a language of defiance, a language employed to create, delineate, and emphasise social boundaries, and even to jeer and provoke 
people (both insiders and outsiders, in public and private), the amount of Norfolk used has decreased because of the social exposure it now receives. Norfolk and Norfolk speakers do not have as much to fight against as in the past, due to the current relatively amicable dealings with the Australian Commonwealth, distant British influences, and other colonial powers. ${ }^{6}$

The ridiculed and stigmatised past associated with the speaking of Norfolk are connected to the often negative perception of events which took place on Pitcairn Island and in Polynesia (e.g. Shapiro 1938). These incidents have since become a source of celebration and even an origin of name generation in the landscape through embracing this past rather than rejecting it. For example, the use of Tahitian personal names has become common on Norfolk, for example, as in Tevarua Lane. This previously unnamed road was named in 2008 in honour of Tevarua, a Tahitian woman who arrived on Pitcairn with the Bounty mutineers. She died in around 1799 and was the consort of Bounty mutineer, Matthew Quintal. Her name is entered as 'Te Walua' in the Pitcairn Register which also lists 'Sarah' and 'Big Sullee' as her other names (Ross and Moverley 1964: 52). The officialising of Tevarua Lane as an iconic road name symbolises an acceptance within the community of the Norfolk Islanders' Tahitian heritage that began in the 1960s. The recognition of this ancestry through a road name is only one example of a renaissance of Polynesian cultural symbolism on Norfolk Island, a method of Indigenisation of a previously non-Indigenous cultural and geographical space. This reawakening is felt in realms of culture such as Tahitian music and dance (see Hayward's 2006 Bounty Chords for an interpretation and micro-ethnography of the music of Pitcairn and Norfolk) and the use of personal names (e.g. Reynolds's 2007 Tahitian Names for Babes: I'oa Tahiti; Wiseman 1977).

\section{Political and Legal Issues: Legislation and Language}

Although Norfolk Island Government legislation does not necessarily need to be honoured by Canberra, Norfolk, a language spoken with differing degrees of proficiency, is the only language in Australia and its territories that can be recognised by the Australian Commonwealth. This has several political implications for what the language is in Australia politically, legally, and legislatively. The Act (2004) is unprecedented in that it was the first time any Australian Commonwealth legislation dealing with language had been written, and it was where the name of the language was officialised 
through its now official name, Norf'k. ${ }^{7}$ Although a small document, its weight and potential influence for claiming linguistic human rights for Norfolk speakers and for the (official) appearance of Norfolk in the public sphere, for example, Norfolk press media, and in the landscape, for example, official and unofficial street and business signage, cannot be underestimated. Common opinion among the Norfolk Islanders, who are Pitcairn Island descendants, is that Norfolk Island is not a part of Australia. However, Norfolk Island's 2899 postcode is a part of the New South Wales postal service and the language is unequivocally a part of Australia's linguistic heritage (Baker 1978).

Norfolk contains lexical and grammatical elements that have their roots in England, St Kitts in the Caribbean (attributable to Bounty mutineer Edward Young), and Polynesia. Norfolk is Indigenous and belongs somewhere, and the fact that it may be described, characterised, or classified as a dialect or mixed language makes little difference to its social and political status as an Australian (contact) language. However, this does problematise what an 'Australian language' is or could be and indeed what an 'Australian Indigenous language' is or could be. Are other Australian contact languages, for example, Gurindji Kriol and Northern Territory Kriol, Indigenous languages? Indeed, although these languages may be mixed to a lesser or larger degree with Australian Indigenous languages, are they, too, Australian Indigenous languages? How are they to be treated legally, and what effect does this treatment have on their linguistic and social status? It is not necessary to answer this question suffice to say that Norfolk falls into a different category altogether: it is an Australian language that does not possess any Australian Indigenous language content. It is Australian because it exists in Australia and it is influential legally because of its legislative status. The issue of whether Pitcairn and Norfolk are Indigenous languages again is intended to be exploratory and work in progress.

\section{Ecologically Versus Non-Ecologically Embedded Languages: Ecolinguistics and Pitcairn and Norfolk}

Having dealt with extra-linguistic issues associated with Norfolk and to a lesser extent Pitcairn, the ecological status of these languages in terms of ecolinguistics and linguistic ecology is now considered more specifically. Although contemporary research has often oversimplified claims regarding the classification of Pitcairn and Norfolk and has generally focussed more on formal 
structural analysis based in secondary sources and conducted by people who themselves never visited the island (e.g. Avram 2003; Gleißner 1997; Holm 2000; Reinecke et al. 1975), taking a social and ecological view on typological classification of these languages raises a different problematic. For, by considering only formal language structure, the intricacies of the social and ecological setting of Pitcairn and Norfolk are lost, obfuscated, or at least not considered.

What I suggest as a means to reconcile some of these problems is to present what I consider a more appropriate method not necessarily to describe (Australian) (non-)Indigenous (contact) languages but to assess and observe how they exist within dynamic social and natural ecologies. What I am considering is whether an introduced contact variety can become intensely ecologically embedded and socially and subsequently linguistically connected to a place over a short time period, namely since the arrival of the Bounty on Pitcairn Island and since the arrival of the Pitcairn Islanders on Norfolk Island. It is possible that this process of being and becoming embedded is increased or decreased according to spatial dynamics. That is, faster processes of linguistic embedding and adaptation may occur in (simpler contact) varieties bounded within spatially restricted environments such as those found on small islands. Analysing small contact languages such as Pitcairn and Norfolk may prove more effective in finding answers to these questions.

Ecolinguistics or the field of language ecology is primarily concerned with two major research areas: firstly, environmental discourse analysis, often termed eco-critical discourse analysis or the language of ecology and environmentalism, and secondly, language ecology and the interactions between humans, mind, and environment, often expressed through lexico-grammatical studies of how humans talk about and adapt linguistically to new and foreign environments, that is, the ecology of language. Extending Ernst Haeckel's (1866) idea that ecology is the study of the mutual interrelations and interactions of species and other entities, one strain of ecolinguistics is defined as the study of the mutual interactions between languages and between a language and its environment. A consideration of the ecological embeddedness of languages is nestled well within ecolinguistic thought. Observing ecological embeddedness in small, minority languages may help us understand the dynamics involved when a population of mixed ancestry arrive in a foreign environment where typologically dissimilar languages are in contact as is the case with Pitcairn and Norfolk. Applying an ecological approach to minority languages small in scope may offer results which are applicable to larger scale, possibly non-minority situations. 
In traditional views of linguistic analysis, languages can be studied without any reference to the biocultural context in which they are used. Detached from their environment, they can be transplanted and replaced by other languages and function as arbitrary codes to express universal cognitive categories. The idea that linguistic practices are detachable from the world suggests that one can distinguish between two prototypical language types: (1) ecologically embedded languages and (2) disconnected languages. These are idealised types, and in reality, most languages are a complex mix between being constructed by their environment and constructing their environment (Mühlhäusler 2003: 2). However, such a split between conceptions of what languages are is useful in an empirical analysis. Using place names as examples, an ecologically embedded language should exhibit the following properties:

1. Words reflect social interaction between humans and their environment, for example, Moo-oo Stone on Norfolk Island is an offshore rock formation with a large amount of moo-oo, or native flax; Out Ha Speckle Side (Out at the Speckled Place) refers to the sandy, speckled seaweed-like coral at the bottom of the sea in a specific offshore location around Pitcairn Island.

2. Lexical and grammatical forms are not regarded as arbitrary, for example, the toponym Side Saff Fly Pass (English: Place Surf Flies Past) as a grammatical unit is a sentence. This place name expresses an esoteric and relatively unknown Norfolk Island toponym form that remembers the nature of the swell on the southwest coast of the island; Pitcairn Island's Dan Fall tells about the relation between dangerous topography and naming.

3. The same word can be used to describe human and other life forms, for example, the Norfolk horg (pig, hog) is used for animals, humans, and even the name of a fishing location. Dar Horg is named after a terrestrial feature that resembles a pig from the sea.

4. The lexicon and grammar of space reflects topography, for example, Out ar Station is in a distant location on Norfolk Island; Up Dubbin on Pitcairn Island is topographically 'up' in comparison to Adamstown which is either 'down' or 'in'.

5. Language is a memory of past interactions between humans and nature, for example, Gun Pit is a concrete structure on the west coast of Norfolk Island built during World War II. It is also the name of the fishing ground Ar Gun Pit, which uses Gun Pit in one of its marks. A diachronic approach is of vital importance to the study of synchronic patterns of language use; Side Dan Cack on Big Jack (the place Dan shat on Big Jack) remembers a fated yet well-remembered event involving humans and their environment. 
An understanding of such interrelated phenomena can be achieved by interacting in real-world situations in the actual ecology where the language is spoken and used every day. Names associated with Norfolk Island tourism, for example, Hibiscus Lodge, Daydreamer Holiday Apartments, and Riggers Retreat, and Pitcairn Island names, for example, Christian's Café and the house Down Fletcher (both referring to mutineer Fletcher Christian) demonstrate how history affects naming and how names become embedded. The vision of these islands as island paradises is reflected in these names. The (re) construction of these environments is seen in many domains of naming including the reintroduction of Polynesian names and a distinct absence of Australian and British anthroponyms on Norfolk Island and Pitcairn Island, respectively.

Due to its size and confined social environment, Pitcairn and Norfolk are languages which necessarily require their speakers to be more densely intertwined with the environment where the language is spoken, that is, it is an ecologically embedded language rather than a detachable one. It is not that any variety of English is not linked to its social and natural environment, but such varieties are possibly more detachable than Norfolk is. Pitcairn and Norfolk, however, are not actually detachable from the society and place where they are spoken, Pitcairn Island and Norfolk Island, respectively. Based on fieldwork interaction with Pitcairn Islanders and Norfolk Islanders, it is clear that speaking these languages in cultural, and to a lesser degree natural, environments away from these islands makes very little cultural or ecological sense. ${ }^{8}$ Any language does real work in the real world; it is not claimed that other (potentially ecologically disconnected) languages like varieties of French spoken in New Caledonia or the Hindi spoken in non-Hindi speaking parts of southern India do not have perlocutionary effect, rather that the domain of perlocution in ecologically embedded languages is different than those languages that are dislocated.

A theoretical characterisation of the Pitcairn and Norfolk languages as ecologically embedded cases of language contact, language development, and language change is warranted. What makes this characterisation particularly significant is that such links had to be established twice, due to the initial arrival of the Bounty mutineers and 21 Polynesians on Pitcairn and the relocation of the entire population of Pitcairn Island to Norfolk Island in 1856. As a result, these processes of adaptation have been deposited twice in the grammar and lexicon of the languages of Pitcairn Island and Norfolk Island. The complex social and environmental history of Pitcairn and Norfolk suggests that an analysis comprising three tiers, that is, structural, social, and ecological can help in further understanding the factors at play when describing such 
languages. Linguists often take for granted that a diachronic perspective will help with a synchronic analysis. The author's research on both languages highlights the importance of new and singular perspectives in linguistic analysis; what works for Pitcairn and Norfolk may not necessarily be applicable to other language ecologies and languages.

\section{Exiting Pitcairn and Norfolk: Future Considerations for Minority Contact Languages, Small Islands, and Linguistic Ecology}

What the Pitcairn and Norfolk examples have shown as regards minority contact languages, small island environments, and linguistic ecology is that small and new contact languages strongly question traditional characterisations and perceptions of language and how they operate in isolated situations. Pitcairn and Norfolk highlight the importance of legislation in recognising and changing the social status of previously ridiculed languages. Because these languages are well known in Oceania and elsewhere, the examples should be relevant not only to assessing and describing the linguistic and social nature of other minority languages in Australia and Oceania, but in questioning how ecologically embedded such languages are.

Whereas the characterisation and use of the descriptor Indigenous is not apt or fitting for characterising languages such as Pitcairn and Norfolk, ascertaining the extent to which such languages are ecologically embedded might help alleviate the problems which plague linguistic typologists, specifically in this case, creolists. The designations ecologically embedded (contact) language and non-ecologically embedded (contact) language were put forward as potentially useful categories for describing what Pitcairn, Norfolk, and other contact languages may be and how they may function in the places where they are spoken. By continually drawing parallels between the past and present status of Australian Indigenous languages and the frequently debased treatment they have received, the Norfolk example offers much insight that may be relevant to Pitcairn and possibly other minority languages, too. To the orthodoxy, Norfolk is not an Australian Indigenous language, nor is Pitcairn an Indigenous language of the Pacific. However, and this is of interest to linguists philosophically and methodologically: what Norfolk is not in terms of its Indigeneity as an Australian Indigenous language may contribute to an understanding of what other Australian Indigenous languages actually are. The same could be said of Pitcairn and other minority languages in Oceania. 
What is suggested is a theoretical characterisation of the Pitcairn and Norfolk languages as ecologically embedded cases of language contact and change in contrast to the ecologically disconnected majority of contact languages and minority languages. What makes this study of language change and language characterisation particularly interesting is that such links had to be established twice, due to the move from Pitcairn Island to Norfolk Island, and that these processes of adaptation have been deposited twice in the grammar and lexicon of the languages of Pitcairn Island and Norfolk Island. This study is even more noteworthy because, as mentioned above, Norfolk has been recognised by UNESCO (2007) as an endangered language (see also Garrett 2006).

There are several linguistic and social issues surrounding Pitcairn and Norfolk that question the use of the label 'language' when describing ways of speaking on the respective islands. These relate primarily to the absence of linguistic norms and have resulted and continue to result in unfocused ways of speaking and writing these languages. Dealing with unfocused linguistic entities with few established standards not only means that unitary labels aiming to marry disparate ways of speaking break down but they may even create problems in establishing how such ways of speaking are documented and represented. Flint's (1979) "stable diglossia", Harrison's (1985) "social setting of Norfolk speech", Laycock's (1989) "cant", and Mühlhäusler's (2008: 104-105) "complex outcome of a mixture of linguistic and social forces" are descriptors that offer the most accurate characterisations of Norfolk, and to a lesser extent of Pitcairn, and they are all based on primary data and fieldwork experience. However, that scholars do not agree on these descriptors is significant for any consideration of its history, ontology, and describing what kind of way of speaking it is.

Like other minority language matters, disputes about how Pitcairn and Norfolk could and should be written (e.g. in official correspondence) and displayed in the public sphere (e.g. in house and interpretive place name signage) have done little to strengthen the languages' vitality and linguistic selfesteem within the respective communities. Family and generational speech variation is the norm and there is often little agreement on the meaning of words and expressions. Subtler aspects such as pronunciation and vowel length and distinguishing present Pitcairn and Norfolk as ways of speaking require more documentation and analysis before accurate descriptions or characterisations can be arrived at. Work into Norfolk by Flint, Harrison, and Laycock led Mühlhäusler (2008: 104-105) to share his misgivings about applying any stark linguistic characterisation or categorisation to Pitcairn and Norfolk together: 
Pitcairn Norfolk is an ideal test case for all kinds of linguistic processes because of its small size, its short history and its restriction with regard to domain and function. But it is not a canonical case of creolization, nor a prototypical Pidgin or mixed language. Rather, it is the complex outcome of a mixture of linguistic and social forces $[\ldots]$

Laycock (1989: 627) described Norfolk as a cant, an insider language, an antilanguage, and a language of defiance: "A cant is a kind of linguistic parasite, in that it cannot exist in isolation, away from the language of the larger community that the cant-speakers are attempting to hide from". Up to the present, Norfolk has not been used to communicate with outsiders and the use of the language has tended to increase when external forces (e.g. Australian political powers) have threatened the Islanders.

To summarise, it is worth making some broad philosophical statements about how the nature of minority languages, small island ecologies, and linguistic ecology relates to linguistics and science in general. Several of these positions were developed during the author's long-term research engagement with Peter Mühlhäusler. First, structural analyses cannot provide complete insight into the how, what, and why of language. Second, islands and their languages provide ideal case studies for observing language development, language change, and language death, the three major research foci of linguistics. Third, small and young languages like pidgins, creoles, and dialects, especially those which developed in small and restrictive social and natural ecologies, offer representative findings applicable to languages with more speaker numbers and which are spoken in larger and more diverse environments. Fourth, some phenomena in the world, like the nature of linguistic form, function, and content, cannot in principle ever be completely known. As such, any semblance of linguistic inquiry must by definition be tentative and incomplete. Fifth, and possibly most importantly, to studies of minority languages and their applicability to the greater field of linguistic science, the ontology and the nature of languages and the persistent existence of singularities and specific case studies rather than clear categories is at issue when documenting and analysing languages. As regards theory and methodology, there is an important gap and difference between our representation of languages as our research objects and what languages actually are. What appears as a shortcoming of science is possibly more an acknowledgment of the nature of the world and how humans use language to interact with the world. While this chapter has advocated a parameter-rich, possibly conclusion-poor approach, it is in realising the complexities of the ontology of language and the restrictedness of the scientific apparatus that linguists can get closer to realising the nature of 
what their research object actually is. It is by paying attention to these five perspectives and their applicability to minority languages within dynamic social and natural ecologies that future inroads in language and environment research may better proceed.

\section{Appendix}

(from https:/www.legislation.gov.au/Details/C2015Q00190 accessed 24 November 2017)

Norfolk Island Language (Norf'K) Act 2004 - Act No. 25 of 2004 An Act to recognise the Norfolk Island Language (Norf'k) as an official language of Norfolk Island.

\section{[Assented to 21 December 2004]}

BE IT ENACTED by the Legislative Assembly of Norfolk Island as follows Short title

1. This Act may be cited as the Norfolk Island Language (Norf'k) Act 2004.

\section{Commencement}

2. This Act commences on the day on which notification of assent is published in the Gazette.

\section{Definitions}

3. In this Act "Norfolk Island Language" or "Norf'k" means the language known as "Norf'k" that is spoken by descendants of the first free settlers of Norfolk Island who were descendants of the settlers of Pitcairn Island.

\section{Acknowledgment of Norf'k}

4. By this enactment, the government and people of Norfolk Island recognise and affirm the Norfolk Island Language (Norf'k) and the right of the people of Norfolk Island to speak and write it freely and without interference or prejudice from government or other persons.

Use of Norf'k 
5. The Norfolk Island Language may be used in all forms of communication between persons of Norfolk Island (but need not be) but when used in official communications must always be accompanied by an accurate translation in the English language.

\section{Notes}

1. Throughout this chapter, the term Indigenous is used with capital I. This is customary practice in Australian linguistics and anthropology.

2. This relates directly to the legal and political position of Norfolk on Norfolk Island and The Act (2004), which is Norfolk Island and hence Australian legislation. Because Norfolk is the only language in Australia and its territories specifically to have legislation, my use of 'legal' and 'political' does not consider other Australian Indigenous languages because none of these languages are legislated.

3. Although Norfolk Island is an external territory of Australia and could be deemed distinct from Australia, politically it is Australia. Despite having its own government, its citizens are Australian and it uses Australian currency. For details on the political and social status of Norfolk Island and the Norfolk Islanders, see Low (2012).

4. This is the first mention of English or the English language in any Australian Commonwealth legislation.

5. Under the entry for 'king', in international phonetic script, Flint translates "you breakin' da King's crown" as "you're speaking bad English". The term bad English on Norfolk Island is inevitably linked with the speaking of Norfolk: "This jargon, which is the everyday medium of conversation between the islanders - adults as well as children - is in no respect a language. It is not even a "patois". It is said to be a mixture of English and Tahitian. As a matter of fact it is bad English, spoken by the Bounty men and imperfectly imitated by the Tahitians" (Anon n.d.).

6. It remains to be seen what the recent 2015 changes to the Australian tax system, which will soon include Norfolk Island, will do to Australia-Norfolk Island dealings and hence the amount of the language spoken. The island's parliament and political system will be replaced with a local council. It is unclear what effect this will have the interaction between mainland and Norfolk Island politics.

7. There has been a fair degree of disagreement with the language name and how it should be spelled. The spelling Norf'k is a technical solution to a problem which has much greater social and psychological considerations. The most obvious reason why Norf'k was chosen over the previous Norfuk is because 
some community members felt the latter bore too much resemblance to the English fuck.

8. Few Norfolk Islanders living away from Norfolk Island speak the language or pass it on to their children. This has also been observed for Pitcairn Islanders living in New Zealand.

\section{References}

Administration of Norfolk Island. (2004). Norfolk Island Language (Norf'k) Act 2004. Norfolk Island: Administration of Norfolk Island.

Anon. (n.d.). Report by Inspector Reay, Norfolk Island Public School, May 30, 1912, 'Education on Norfolk Island', Box 4, Folder 12, Flint Collection, Fryer Library, University of Queensland, Brisbane.

Avram, A. A. (2003). Pitkern and Norfolk Revisited: Is Pitkern-Norfolk and Atlantic Creole Spoken in the Pacific? English Today, 19(3), 44-49.

Baker, S. J. (1978). The Australian Language (3rd ed.). Milsons Point: Currawong Press.

Dobrin, L., Austin, P. K., \& Nathan, D. (2007). Dying to Be Counted: The Commodification of Endangered Languages in Documentary Linguistics. In P. K. Austin, O. Bond, \& D. Nathan (Eds.), Proceedings of Conference on Language Documentation and Linguistic Theory (pp. 37-52). London: SOAS.

Eira, C., Magdalena, M., \& Mühlhäusler, P. (n.d.). Draft Norfolk School Grammar. Adelaide: Discipline of Linguistics, University of Adelaide.

Evans, G. (2009). Orn'sehn [At the Beach]. Norfolk Island: Gaye Evans.

Flint, E. (1964). The Language of Norfolk Island. In A. S. C. Ross \& A. W. Moverley (Eds.), The Pitcairnese Language with contributions by E. Schubert, H. E. and Alaric Maude, E. H. Flint and A. C. Gimson (pp. 189-206). London: André Deutsch.

Flint, E. (1979). Stable Diglossia in Norfolk Island. In W. F. Mackey \& J. Ornstein (Eds.), Sociolinguistic Studies in Language Contact: Methods and Cases (pp. 295-333). The Hague: Mouton de Gruyter.

Garrett, P. B. (2006). Contact Languages as "Endangered" Languages: What Is There to Lose? Journal of Pidgin and Creole Languages, 21(1), 175-190.

Gleißner, A. (1997). The Dialect of Norfolk Island as Compared to Other Creoles. Master's Thesis, University of Regensburg.

Haeckel, E. (1866). Generelle Morphologie der Organismen-Allgemeine Grundzüge der organischen Formen-Wissenschaft, mechanisch begründet durch die von Charles Darwin reformierte Descendenz-Theorie. Zweiter Band: Allgemeine Entwickelungsgeschichte der Organismen. Berlin: Verlag von Georg Reimer.

Harrison, S. (1985). The Social Setting of Norfolk Speech. English World-Wide, 6(1), 131-153. 
Hayward, P. (2006). Bounty Chords: Music, Dance, and Cultural Heritage on Norfolk and Pitcairn Islands. London: John Libbey \& Company.

Holm, J. (2000). An Introduction to Pidgins and Creoles. Cambridge: Cambridge University Press.

Källgård, A. (n.d.) Pitcairn and Pitkern Revisited: A New Role for a Small Island Language. Unpublished manuscript.

Latham, T. (2005). Norfolk: Island of Secrets: The Mystery of Janelle Patton's Death. Crows Nest: Allen and Unwin.

Laycock, D. C. (1989). The Status of Pitcairn-Norfolk: Creole, Dialect, or Cant? In U. Ammon (Ed.), Status and Function of Languages and Language Varieties (pp. 608-629). Berlin: Walter de Gruyter.

Low, M. (2012). Putting Down Roots: Belonging and cultural Identity on Norfolk Island. $\mathrm{PhD}$ Thesis, University of Western Australia.

Marrington, P. (1991). In the Sweet Bye and Bye: Reminiscences of a Norfolk Islander. Sydney: Reed.

Mühlhäusler, P. (2003). Language of Environment - Environment of Language. London: Battlebridge.

Mühlhäusler, P. (2005, June 15). The Restoration of Bilingualism on Norfolk Island and the Far West Coast of South Australia. Paper Presented at the 'Penser le bilinguisme autrement' Symposium, Guebwiller.

Mühlhäusler, P. (2007a, September). Is Pitkern-Norf'k a creole? Paper Presented at the Australian Linguistic Society Conference, Adelaide.

Mühlhäusler, P. (2007b). The Pitkern-Norf'k Language and Education. English World-Wide, 28(3), 215-247.

Mühlhäusler, P. (2008). Multifunctionality in Pitkern-Norf'k and Tok Pisin. Journal of Pidgin and Creole Languages, 23(1), 75-113.

Mühlhäusler, P. (2011). Some Notes on the Ontology of Norf'k. Language and Communication, 33, 673-679.

Mühlhäusler, P. (2015). From Despised Jargon to Language of Education: Recent Developments in the Teaching of Norf'k (Norfolk Island, South Pacific). In C. A. Volker \& F. E. Anderson (Eds.), Education in Languages of Lesser Power: AsiaPacific Perspectives (pp. 223-241). Amsterdam/Philadelphia: John Benjamins.

Mühlhäusler, P. (n.d.). A Writing System for the Norf'k Language. Unpublished manuscript.

Nash, J. (2013). Insular Toponymies: Place-Naming on Norfolk Island, South Pacific and Dudley Peninsula, Kangaroo Island. Amsterdam/Philadelphia: John Benjamins.

Nash, J. (2016). Ecologically Embedded Languages, Cumulative Grammars, and Island Ecologies. Acta Linguistica Hafniensia, 48(2), 161-170.

Nash, J. (2017). Pitcairn Island, Island Toponymies, and Fishing Ground Names: Towards the Possibility of a Peaceful Onshore and Offshore Reconciliation. Journal of Territorial and Maritime Studies, 4(1), 98-108. 
Reinecke, J. E., DeCamp, D., Hancock, I. F., Tsuzaki, S. M., \& Wood, R. E. (1975). A Bibliography of Pidgin and Creole Linguistics. Honolulu: The University Press of Hawaii.

Reynolds, P. (2007). Tahitian Names for Babes: I'oa Tahiti. Norfolk Island: 'Ana' Ana Publishing.

Ross, A. S. C., \& Moverley, A. W. (1964). The Pitcairnese Language with contributions by E. Schubert, H. E. and Alaric Maude, E. H. Flint and A. C. Gimson. London: André Deutsch.

Shapiro, H. L. (1938). The Heritage of the Bounty: The Story of Pitcairn Through Six Generations. London: Victor Gollancz.

United Nations Educational, Scientific, and Cultural Organization (UNESCO). (2007). Degree of Endangerment of the Norf'k Language (Norfolk Island, South Pacific). Unpublished manuscript.

Walsh, M. (2005). Will Indigenous Languages Survive? Annual Review of Anthropology, 34, 293-315.

Warren, M. (2007). Mi Bas Side orn Pitcairn [My Favourite Place on Pitcairn]. Pitcairn Island: M. Warren.

Wiseman, B. (1977). Living on Norfolk Island. Norfolk Island: Photopress International. 